\title{
Odontome- Revisted
}

Neha Jain ${ }^{1}$, Ajay Pillai ${ }^{2}$, Amirthaa Varshini ${ }^{3}$, Dhwani Kawadkar ${ }^{4}$, Kriti Dubey ${ }^{5}$ and Ajita Singh ${ }^{6}$

${ }^{1}$ MDS. Reader. Department of Oral and Maxillofacial Surgery, People Dental Academy, Bhopal.

${ }^{2}$ MDS. Professor and Head. Department of Oral and Maxillofacial Surgery, People Dental Academy, Bhopal.

${ }^{3}$ MDS. Senior Lecturer. Department of Oral and Maxillofacial Surgery, People Dental Academy, Bhopal.

${ }^{4}$ Post Graduate Student. Department of Oral and Maxillofacial Surgery, People Dental Academy, Bhopal.

${ }^{5}$ MDS. Consultant. Private Practioner. Bhopal

${ }^{6}$ MDS. Reader. Department of Oral Medicine and Radiology, Rishiraj College of Dental Science and Research Center. Bhopal.

*Corresponding Author: Neha Jain, Room No 101, Dept of Oral \& Maxillofacial Surgery, People's Dental Academy, Bhopal.

Received date: September 29, 2021; Accepted date: October 15, 2021; Published date: October 26,2021

Citation: Neha Jain, Ajay Pillai, Amirthaa Varshini, Dhwani Kawadkar, Kriti Dubey and Ajita Singh (2021). Odontome- Revisted. J Clinical Research and Reports, 9(2); DOI:10.31579/2690-1919/203

Copyright: (C) 2021 Neha Jain. This is an open access article distributed under the Creative Commons Attribution License, which permits unrestricted use, distribution, and reproduction in any medium, provided the original work is properly cited.

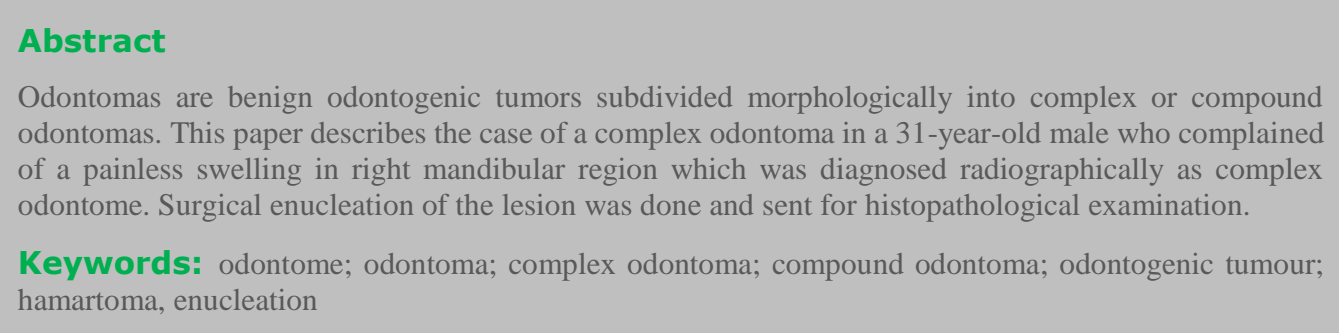

\section{Introduction}

The term odontoma was coined firstly by Pierre Paul Broca in 1867, who described it as tumours formed by the disproportionate transitory or full growth of dental tissues [1]. Odontomes are the most common benign odontogenic tumours of epithelial and mesenchymal origin accounting for $22 \%$ of the odontogenic tumors [2]. Odontomes are usually seen on radiograph as a small, solitary, or multiple radiopaque lesions which may because delayed eruption of teeth, retention of primary teeth or displacement of teeth [3]. According to radiographic, microscopic, and clinical features, two types of odontomas are recognized: Complex and compound odontomas. Compound odontoma forms a conglomeration of small structures resembling teeth, whereas a complex odontoma forms an irregular mass in a disorderly pattern [4].

Odontomas are discovered during the second and third decades of life [5]. The compound odontoma is slightly more common than the complex odontoma. The majority of odontomas seen in the anterior region of the jaws are compound in nature $(61 \%)$, whereas the majority observed in the posterior region is complex in nature (34\%) [6]. The compound odontome most frequently occurred in incisor cuspid region of the maxilla in contrast to the complex odontome which were commonly found in molar and premolar region of the mandible [7]. They are observed more in right side of the jaws (compound 62\%, complex 68\%) [6].

\begin{tabular}{|l|l|l|}
\hline Feature & Compound Odontome & Complex odontome \\
\hline Definition & $\begin{array}{l}\text { Malformation in which all dental tissues are } \\
\text { arranged in a more orderly pattern than in the } \\
\text { complex odontoma so that the lesion consists of } \\
\text { many tooth-like structures }\end{array}$ & $\begin{array}{l}\text { Malformation in which all dental } \\
\text { tissues are arranged in a hapazard } \\
\text { manner. }\end{array}$ \\
\hline Shape & $\begin{array}{l}\text { Regularly shaped, solitary or multiple small } \\
\text { denticles or tooth like structures }\end{array}$ & $\begin{array}{l}\text { Amorphous conglomeration of dental } \\
\text { tissues }\end{array}$ \\
\hline Appearance & $\begin{array}{l}\text { Bizzare peg shaped teeth show anatomic } \\
\text { resemblance to normal teeth }\end{array}$ & $\begin{array}{l}\text { An irregular mass with no morphologic } \\
\text { similarity. }\end{array}$ \\
\hline Incidence & 9 to $37 \%$ & 5 to $30 \%$ \\
\hline
\end{tabular}




\begin{tabular}{|l|l|l|}
\hline Sex & Female predilection is seen \\
\hline Age & $\begin{array}{l}\text { Commonly seen in second and third decades. Both the type of odontomas are seen in younger } \\
\text { individual with mean ages } 14.8 \text { and } 20.3 \text { years respectively. }\end{array}$ \\
\hline Site & Commonly situated in the anterior region of maxilla & Posterior region of mandible \\
\hline Side and dentition & $\begin{array}{l}\text { Both type of odontomas occurred more frequently on the right side of the jaw than on the left. } \\
\text { Commonly occur in permanent dentition and are rarely seen in primary dentition }\end{array}$ \\
\hline Sign and symptoms & $\begin{array}{l}\text { Asymptomatic, although occasionally signs and symptoms relating to their presence do occur } \\
\text { symptoms - These generally consist of - Unerupted or impacted teeth, retained deciduous } \\
\text { teeth, swelling, evidence of infection and displacement of teeth and malocclusion. } \\
\text { - Compound odontome rarely cause expansion of bone but in complex odontome marked bony } \\
\text { expansion has been observed. }\end{array}$ \\
\hline Radiological feature & $\begin{array}{l}\text { Comparatively well-organized malformed teeth or } \\
\text { tooth-like structures or denticles of varying size and } \\
\text { shape surrounded by a narrow radiolucent zone }\end{array}$ & $\begin{array}{l}\text { Irregular mass of calcified material } \\
\text { surrounded by a narrow radiolucent } \\
\text { band with smooth outer periphery }\end{array}$ \\
\hline Histopathology & $\begin{array}{l}\text { Tooth-like structures with central cores of pulp } \\
\text { tissue that are encased in shells of dentin and } \\
\text { partially covered by enamel, surrounded by a } \\
\text { fibrous capsule similar to the follicle surrounding a } \\
\text { normal tooth. }\end{array}$ & $\begin{array}{l}\text { Microscopically they consist of } \\
\text { haphazard conglomerates of dentin } \\
\text { enamel matrix, enamel, cementum and } \\
\text { pulp tissue. }\end{array}$ \\
\hline Treatment & \begin{tabular}{l} 
Surgical enucleation \\
\hline
\end{tabular} \\
\hline
\end{tabular}

Table 1: Difference between compound odontoma and complex odontoma [8]

\section{Case Report}

A 31 year old male patient reported to the outpatient department of Oral and Maxillofacial surgery, People's Dental Academy, Bhopal with a complaint of painless swelling in the lower right back tooth region from last 5-6 months. Initially the swelling was pinhead sized which has progressively increased over a period of 6 month to attain present size.

On examination, no facial asymmetery was noted extraorally. On intraoral examination single, well defined, oval, non tender swelling of $4 * 3 \mathrm{~cm}$ was present in buccal vestibule extending from 45 to 47 obliterating the buccal vestibule (figure 1). The swelling also seen in lingual vestibule in 46 and 47 region (figure 2). The color of the swelling was normal as that of mucosa. On palpation the swelling was smooth and firm hard in consistency. No evidence of crepitus or pathological fracture was seen. Hard tissue examination revealed buccal pits restored with amalgam restoration in relation to 46 and 47 . The tooth 46 was found to be tender on percussion.

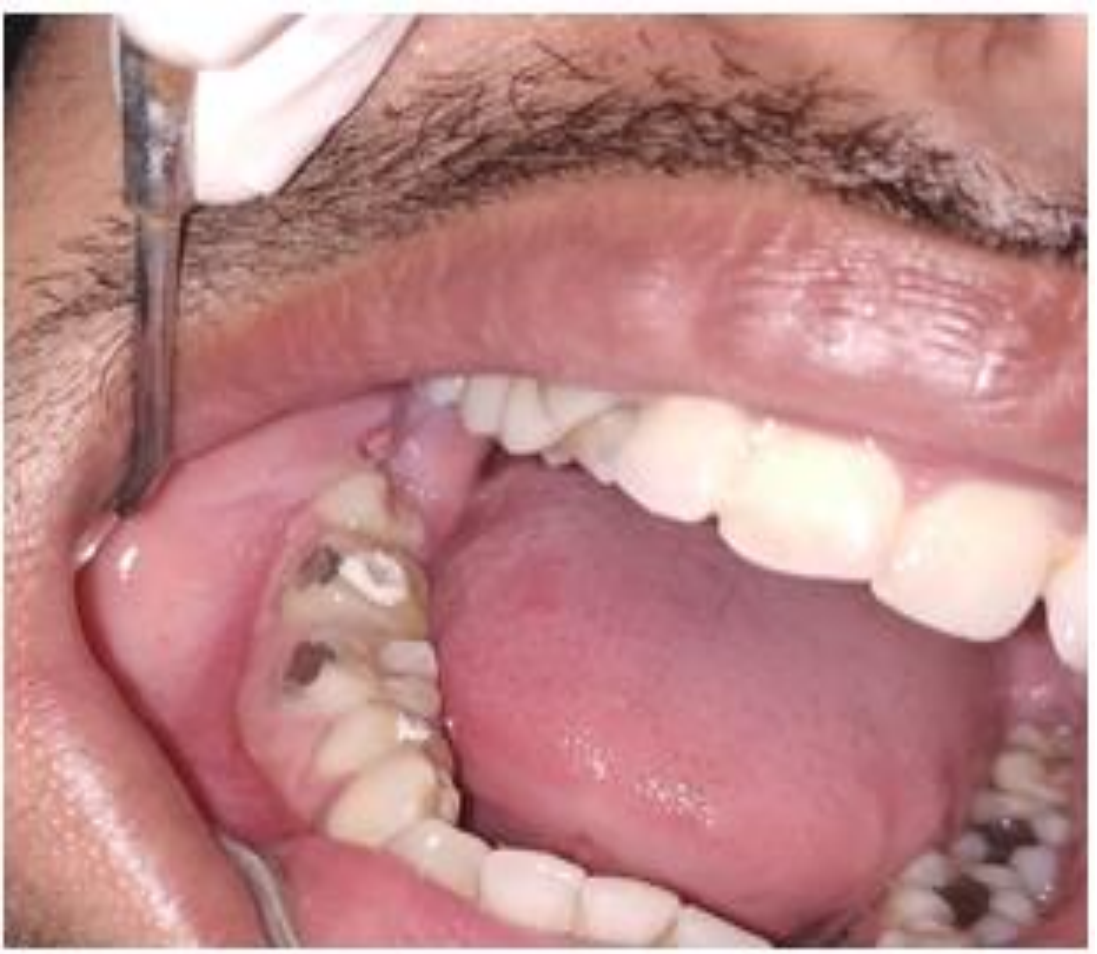

Figure 1: Buccal vestibular extension of the lesion 


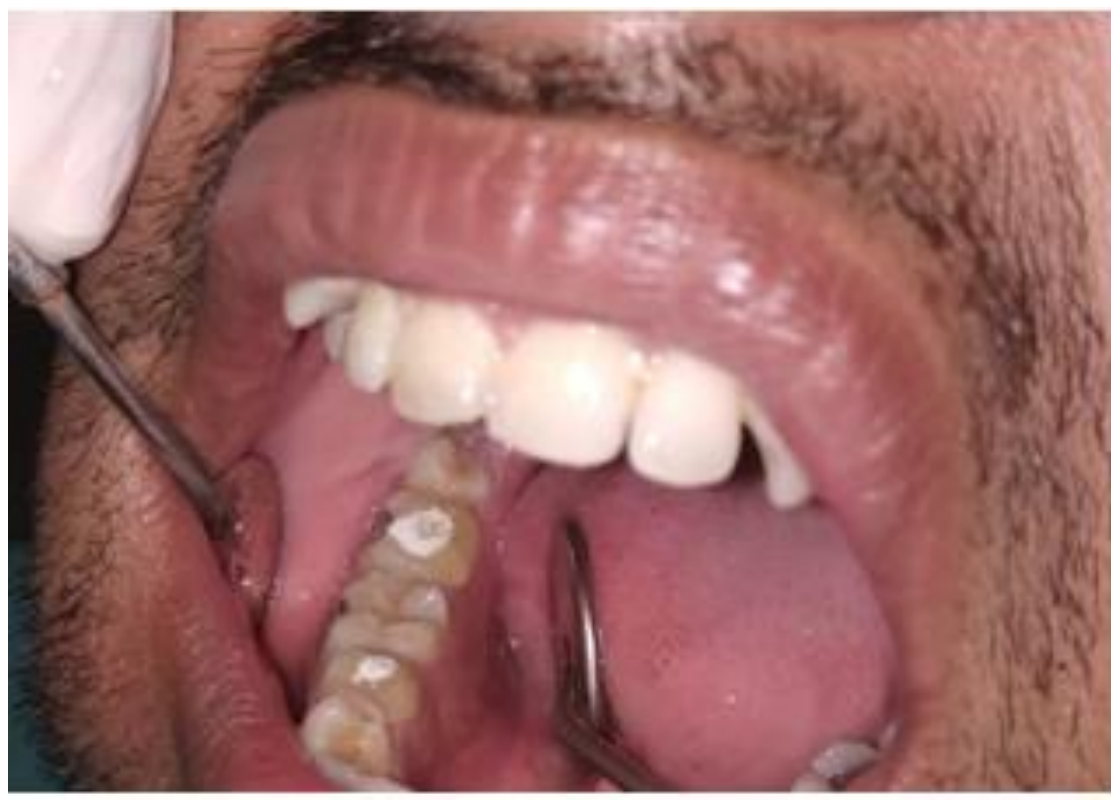

Figure 2: Lingual extension of the lesion

A provisional diagnosis of periapical cyst was made.

OPG revealed an ill-defined radiopacity present in relation to the apex of
46. The radiopaque mass was encased by a well -defined radiolucent borders suggestive of the lesion being well localized and well circumscribed. (Figure 3)

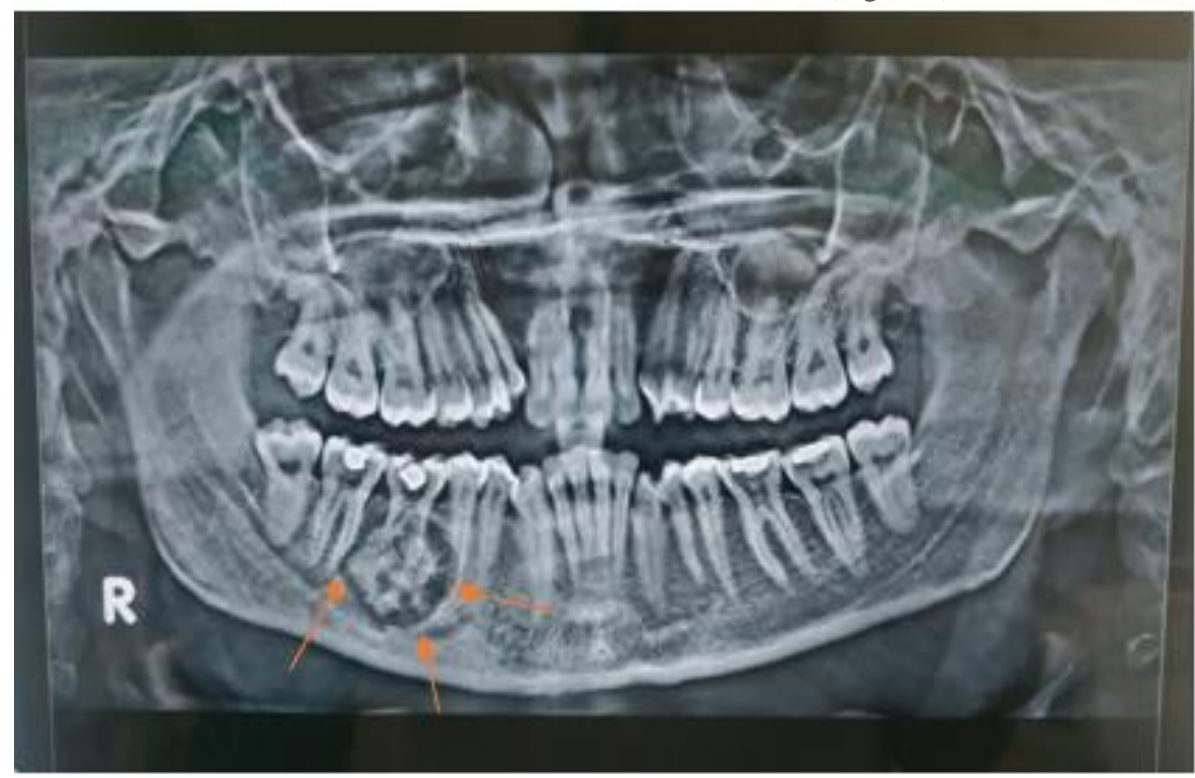

Figure 3: $O P G$ revealing the radioopacity at the root apex of 46

Upon corelating the clinical and radiographical findings the diagnosis of complex odontoma was made.

Excisional biopsy was planned under GA. Root canal treatment was done for 47 and 45 prior to the surgery. All the pre-liminary investigations including Total blood count, serology, BT, CT, blood group, LFT, KFT, serum electrolytes, Chest X-ray and ECG were performed.
Following all the aseptic measures before the surgery, trapezoidal incision was given extending from 43 to 48 region. Releasing incision was placed in the canine and $3^{\text {rd }}$ molar region and mucoperiosteal flap was raised to visualize the area completely. 46 was extracted then bone was removed buccally till we reached the lesion (Figure 4). 


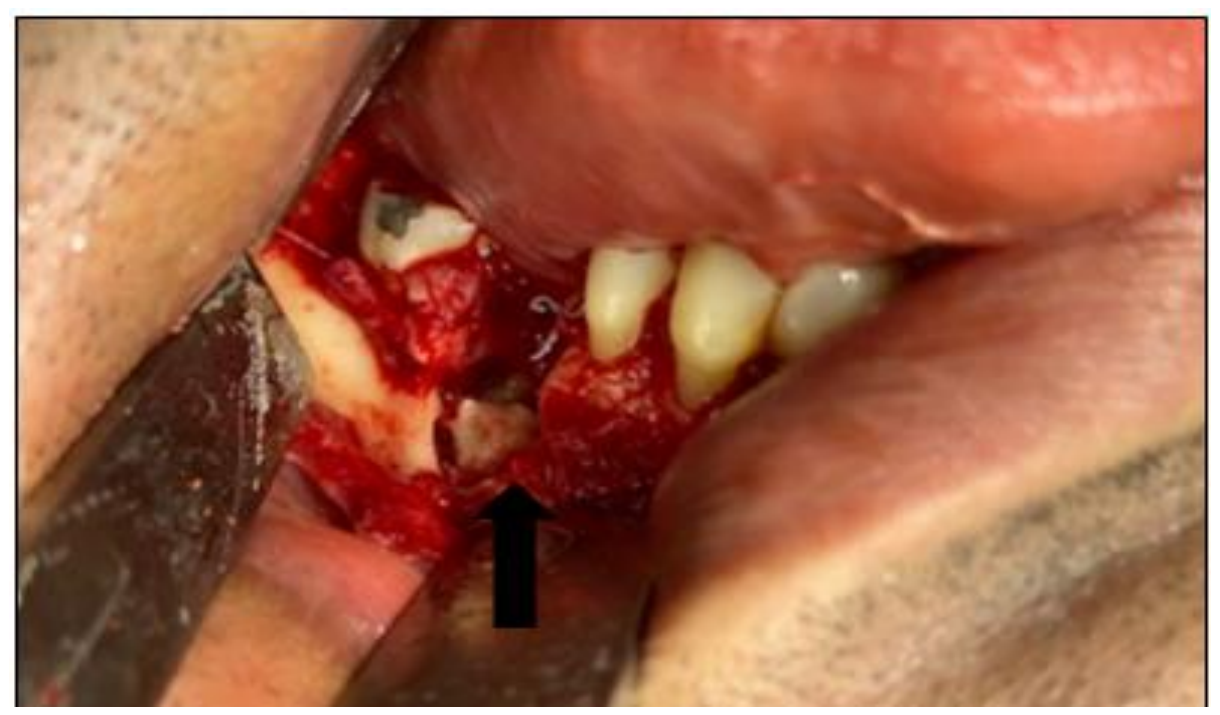

Figure 4: Exposed odontoma

The bony mass was sectioned and delivered in parts and sent for histopathological evaluation (Figure 5).

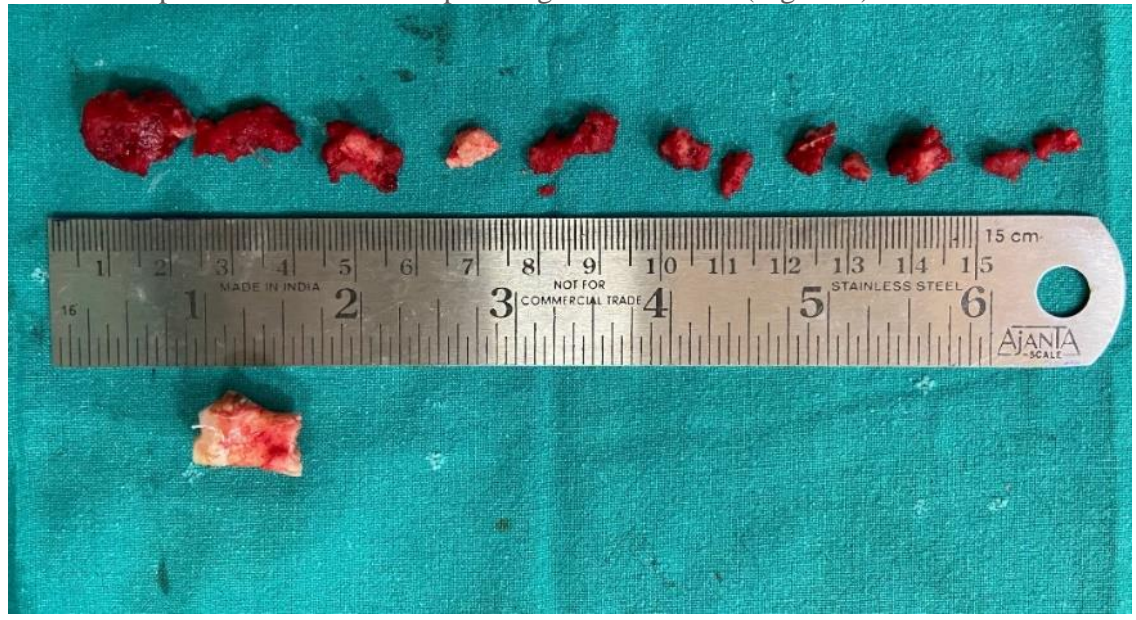

Figure 5: Removal of odontoma and tooth

Curettage was done and the bony cavity was packed with PRF to accelerate healing. The flap was then approximated with resorbable 3-0 vicryl sutures. (Figure 6)

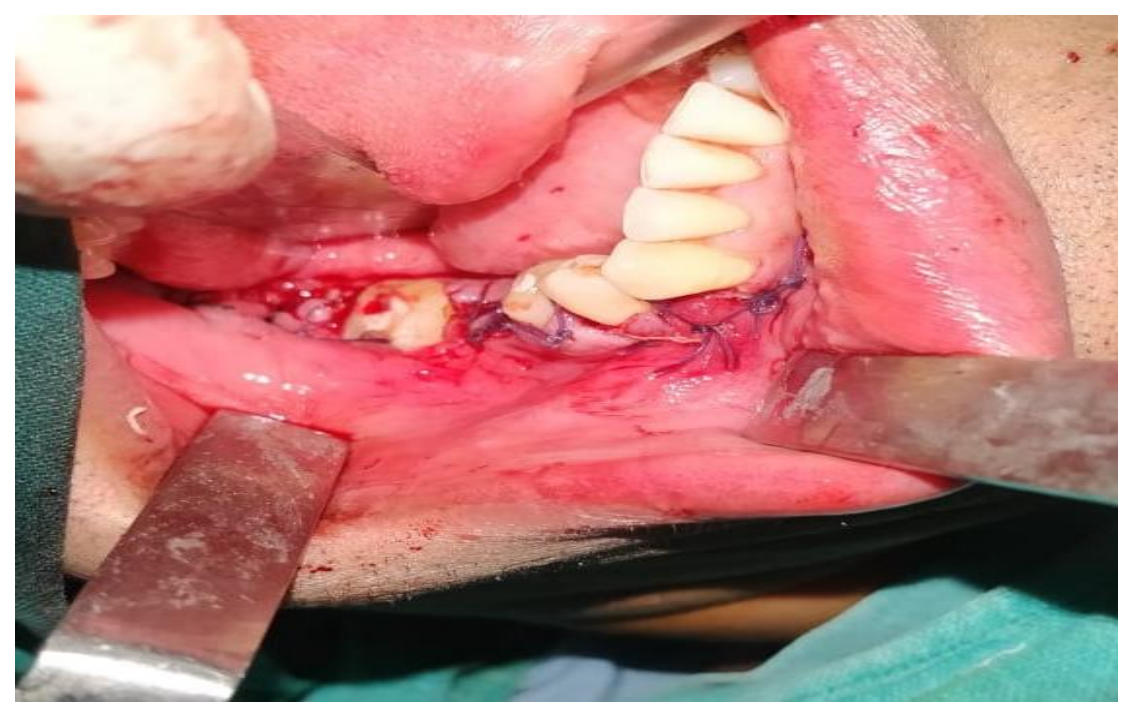


Post-operative medications to control pain, post-operative edema and infection were prescribed. Mouthwash was advised to maintain oral hygiene. Patient was recalled after 7 days for suture removal and post op OPG was done. (Figure 7).

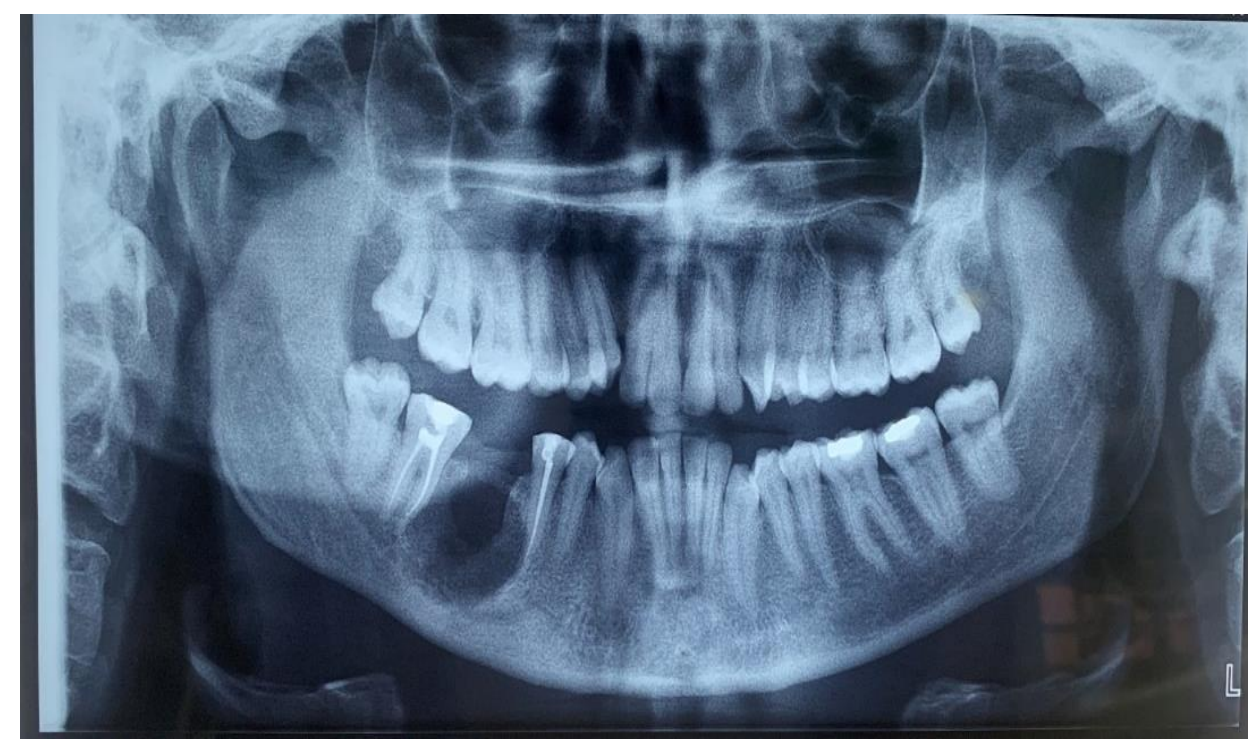

Figure 7: Post-operative OPG

On histopathological examination of the excised lesion the diagnosis of odontoma was confirmed. (Figure 8)

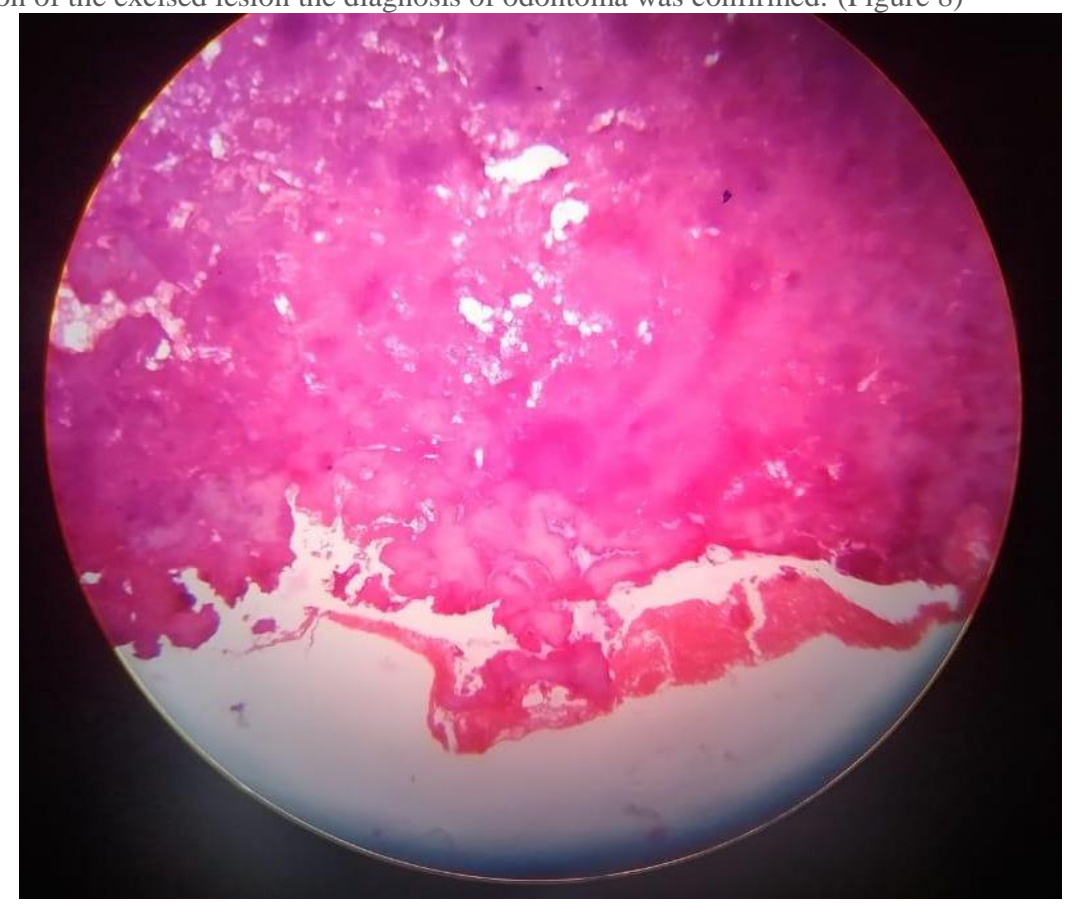

Figure 8: Histopathological appearance of the odontoma

\section{Discussion}

Odontoma are benign odontogenic tumor composed of enamel, dentine, cementum and pulpal tissue.

\section{Etiology of odontoma [9]}

1. Trauma to the primary dentition

2. Infection from deciduous predecessor

3. Genetically inherited
4. Associated with anomalies like Hermann's and Gardner's syndrome

5. Hyperactivity of the ameloblast, cell rest of serres, dental lamina remnants

6. Genetic mutation causing aberrations in signaling pathways controlling tooth development.

\section{Classification}

Several Classification has been given to odontome 
A) In 1914, Gabell, James, and Payne grouped odontome according to their developmental origin: [10]
1) epithelial
2) mesodermal
3) composite (epithelial and mesodermal)

B) In 1946, Thoma and Goldman proposed a classification which is as follows: [11]

1) Geminated composite odontomes: Fusion of two or more, more or less well-developed teeth

2) Compound composite odontomes: made up of more or less rudimentary teeth.

3) Complex composite odontomes: calcified structure without any resemblance to the normal anatomical dental tissues.

4) Dilated odontomes: Distinct enlarment of crown or root part of tooth

5) Cystic odontomes: an odontome encased all around by fibrous connective tissue

C) According to the World Health Organization (WHO) classification, odontomes can be divided into three groups: [12]

1. Complex odontome: In this type the calcified dental tissues are arranged in a haphazard manner which morphologically does not resemble to rudimentary teeth.

2. Compound odontome: composed of odontogenic tissues which are arranged in an orderly pattern, which result in many teeth-like structures, but without morphological resemblance to normal teeth.

3. Ameloblastic fibro-odontome: In this subtype varying amounts of calcified dental tissue and dental papilla-like tissue, resembling an ameloblastic fibroma is seen. This type has been considered as an immature precursor of complex odontoma.

D) On the basis of radiographical representation and microscopic features two types of odontoma are seen, namely: [13]

1) Compound odontome

2) Complex odontome

E) According to their position within the jaws: [13]

1. Intraosseous (erupted odontoma): They occur inside the bone and may erupt into the oral cavity.

2. Extraosseous or peripheral odontomas: These are odontomas occurring in the soft tissue covering the tooth bearing portions of the jaws, having a tendency to exfoliate.

\section{Clinical presentation}

Usually the odontoma are asymptomatic, discovered routinely during radiographs. Occasionally signs and symptoms do exist which may be observed in the form of unerupted or impacted teeth, retained deciduous teeth, swelling, infection, displacement or devitalization of tooth. Compound odontomas rarely cause bony expansion but complex odontomes may lead to marked bony expansion [8].

Since odontoma are usually intraosseous type so they diagnosed only by radiograph. Extraosseous form can be manually palpated. But the distinguishable type can only be diagnosed on radiograph. The radiographic appearance of complex and compound odontoma is mentioned in (table 1).

\section{Treatment}

Surgical excision or enucleation of the odontoma is the treatment of choice. Since odontoma are benign encapsulated odontogenic tumors which have little propensity to grow and reoccur but as mentioned earlier it can cause bony expansion, cystic changes, interruption of tooth movement, etc. so surgical removal is necessary.

Early diagnosis and treatment of odontomas led to better prognosis, cost effective and prevent relapse and devitalization and displacement of tooth

\section{Conclusion}

Odontomas rarely erupt into the oral cavity and tend to be associated with impacted, erupted as well as retained teeth. They are diagnosed on a thorough visual and radiographic examination. Compound odontoma on radiograph shows tooth like structures whereas compound odontoma presented as irregular calcific mass. The enucleation of the odontoma and extraction of the associated tooth along with root canal treatment for both the adjacent teeth is done for best outcomes.

\section{References:}

1. Philipsen HP, Reichart PA. (2006). Classification of odontogenic tumours: A historical review. J Oral Pathol Med 2006; 35:525529.

2. Bhaskar, SN. (1986). Odontogenic tumors of jaws. In: Synopsis of oral pathology. 7th ed. US: Elsevier Mosby Year Book 1986. pp. 292- 303.

3. Snawder KD. (1974). Delayed eruption of the anterior primary teeth and their management: report of a case. ASDC J Dent Child $1974 ; 41: 382-384$.

4. Junquera L, de Vicente JC, Roig P, Olay S, Rodriguez-Recio O. (2005). Intraosseous odontoma erupted into the oral cavity: An unusual pathology. Med Oral Patol Oral Cir Bucal 2005; 10:248 $-251$.

5. Budnick SD. (1976). Compound and complex odontomas. Oral Surg Oral Med Oral Pathol 1976 Oct; 42(4):501-506.

6. Shafer, GW.; Hine, MK.; Levy BM. (1983). A textbook of oral pathology. In: Rajendran R, editor. 4th ed. US, Philadelphia: WB Saunders 1983. pp. 308-311.

7. Kharbanda OP, Saimbi CS, Kharbanda R. (1986). Odontome: A case report. J Indian Dent Assoc 1986 Jul; 58(6):269-271.

8. V Satish, Maganur C Prabhadevi, Rajesh Sharma. (2011). Odontome: A Brief Overview. International Journal of Clinical Pediatric Dentistry, September-December 2011; 4(3):177-185.

9. Deepali Patekar, Supriya Kheur, Archana A. Gupta. (2018). Odontoma - A brief overview. Journal of Oral Disease Markers 2018; 2:23-25.

10. Patil S, Rahman F, et al. (2012). Odontomas: review of literature and report of a case. J Oral Maxillofac Pathol 2012; 3:224-227.

11. Syed MR, Meghana SM, et al. (2006). Bilateral complex odontomas in mandible. J Oral Maxillofac Pathol 2006; 10:89_ 91.

12. Tomizawa M, Otsuka Y, et al. (2005). Clinical observations of odontomas in Japanese children: 39 cases including one recurrent case. Int J Paediatr Dent 2005; 15:37-43.

13. Chirag Suhane, Nikhil Srivastava, Vivek Rana and Noopur Kaushik. (2020). Complex: A Rare case report with literature review. International Journal of Advanced research 8(03) 364370. 
This work is licensed under Creative Commons Attribution 4.0 License

To Submit Your Article Click Here: Submit Manuscript

DOI: $10.31579 / 2693-4787 / 028$
Ready to submit your research? Choose Auctores and benefit from:

* fast, convenient online submission

* rigorous peer review by experienced research in your field

* rapid publication on acceptance

* authors retain copyrights

* unique DOI for all articles

* immediate, unrestricted online access

At Auctores, research is always in progress.

Learn https://auctoresonline.org/journals/clinical-oncology-researchand-reports 